\title{
The "thoracic endovascular aortic repair-first" strategy for acute type A dissection with mesenteric malperfusion: Initial results compared with conventional algorithms
}

\author{
Bradley G. Leshnower, MD, ${ }^{a}$ W. Brent Keeling, MD, ${ }^{a}$ Yazan M. Duwayri, MD, ${ }^{b}$ \\ William D. Jordan, Jr, MD, ${ }^{b}$ and Edward P. Chen, MD ${ }^{a}$
}

\section{ABSTRACT}

Objective: Acute type A dissection with mesenteric malperfusion is a rare but lethal variant of aortic dissection. This study examines outcomes from various treatment algorithms.

Methods: A review from 2003 to 2017 of the Emory Aortic Database identified 34 patients who presented with acute type A dissection with mesenteric malperfusion. Outcomes from 4 different treatment strategies were analyzed: ascending aortic/arch replacement followed by laparotomy $(n=13)$, axillary-bifemoral artery bypass followed by ascending/arch replacement $(n=3)$; ascending/arch and concomitant antegrade thoracic endovascular aortic repair (TEVAR) $(n=5)$, and TEVAR followed by delayed ascending/arch replacement (TEVAR-1st) $(\mathrm{n}=13)$.

Results: The mean age of all patients was $53 \pm 13$ years and was equivalent among the groups. The incidence of concomitant renal and ileofemoral malperfusion was $52 \%$ and $41 \%$, and the initial serum lactate level was $4.3 \pm 2.1 \mathrm{mmol} / \mathrm{L}$. Overall mortality was $55.8 \%$. In the ascending aortic/arch replacement followed by laparotomy group, $77 \%$ of patients had postoperative bowel necrosis or intractable acidosis and the mortality was $69.2 \%$. All patients in the axillary-bifemoral artery bypass followed by ascending/arch replacement group survived, but $66 \%$ required postoperative dialysis. In the ascending/arch and concomitant antegrade/TEVAR group, the mortality was $80 \%$ secondary to persistent postoperative bowel necrosis or intractable acidosis. Three patients in the TEVAR-1st group died before aortic replacement. In the 10 patients who underwent TEVAR followed by delayed aortic replacement, the mortality was $30 \%$. There were no cases of postoperative bowel necrosis or intractable acidosis in the TEVAR-1st group.

Conclusions: The TEVAR-1st strategy delays central aortic replacement until end-organ ischemia has resolved. This novel paradigm serves as a bridge to decision, and may improve survival compared with conventional treatment strategies in acute type A dissection with mesenteric malperfusion. (J Thorac Cardiovasc Surg 2019;158:1516-24)

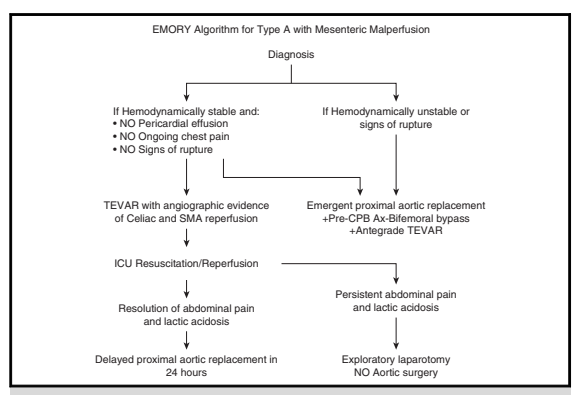

Contemporary algorithm for acute type A dissection with mesenteric malperfusion.

\section{Central Message}

In patients with acute type A dissection with mesenteric malperfusion, endovascular reperfusion and resolution of end-organ ischemia before central aortic repair may improve survival.

\section{Perspective}

Acute type A dissection with mesenteric malperfusion carries the highest mortality of all malperfusion syndromes. Conventional therapy consisting of emergent ascending aortic replacement and bowel resection has resulted in poor outcomes. We propose a novel paradigm of TEVAR followed by delayed ascending aortic replacement that may improve survival compared with conventional strategies.

See Commentaries on pages 1525 and 1527.
From the Divisions of ${ }^{\mathrm{a} C}$ ardiothoracic Surgery and ${ }^{\mathrm{b}}$ Vascular and Endovascular Therapy, Department of Surgery, Emory University School of Medicine, Atlanta, Ga. Read at the 2018 Aortic Symposium of the American Association for Thoracic Surgery, New York, New York, April 26-27, 2018.

Received for publication May 6, 2018; revisions received Dec 17, 2018; accepted for publication Jan 3, 2019; available ahead of print March 8, 2019.

Address for reprints: Bradley G. Leshnower, MD, Division of Cardiothoracic Surgery, Department of Surgery, Emory University School of Medicine, 1365 Clifton Rd, NE, Ste A 2213, Atlanta, GA 30322 (E-mail: bleshno@emory.edu). 0022-5223/\$36.00

Copyright (c) 2019 by The American Association for Thoracic Surgery https://doi.org/10.1016/j.jtcvs.2019.01.116
Acute type A aortic dissection complicated by mesenteric malperfusion (ATAMM) represents the most challenging and lethal variant of all malperfusion syndromes associated with aortic dissection. ${ }^{1-3}$ Mortality rates range from $41 \%$ to

To view the AATS Meeting Webcast, see the URL next to the webcast thumbnail. 


\section{Abbreviations and Acronyms \\ ASC/LAP = ascending and arch replacement, followed by laparotomy \\ ASC/TEVAR = ascending and arch replacement with concomitant antegrade TEVAR \\ Ax-Bifem/ASC $=$ precardiopulmonary bypass axillary artery-bifemoral artery bypass, followed by ascending/ arch replacement
ATAMM
$=$ acute type $\mathrm{A}$ aortic dissection complicated by mesenteric malperfusion
HCA
IVUS $=$ hypothermic circulatory arrest
TEVAR
$=$ intravascular ultrasound
$=$ thoracic endovascular aortic repair
TEVAR-1st = TEVAR followed by ascending/ arch replacement

$100 \%$, including a $63 \%$ in-house mortality rate in a series of 68 patients from the International Registry of Aortic Dissection database..$^{1-5}$ Several factors contribute to the dismal outcomes with ATAMM. The initial challenge is making the diagnosis. Only $60 \%$ of patients present with abdominal pain, and there are no laboratory studies that have the sensitivity and specificity to accurately identify the presence or absence of gastrointestinal ischemia. ${ }^{6}$ Often ATAMM is associated with liver, renal, and ileofemoral malperfusion due to true lumen compression throughout the abdominal aorta, which increases the morbidity and mortality of this syndrome. Finally, as in many cases of type A dissection, there is often a significant delay between diagnosis and treatment. When this occurs, the prolonged reduction in blood flow to the splanchnic circulation can result in irreversible microvascular vasospasm and transmural intestinal ischemia despite restoration of normal blood flow to the visceral segment of the aorta.

Historically, the standard treatment of ATAMM has been emergent proximal aortic replacement followed by exploratory laparotomy and bowel resection. Our own institutional results with this strategy have mirrored the poor outcomes reported in the literature and prompted a search for alternative treatment strategies. ${ }^{1-5}$ Lessons learned from our experience with thoracic endovascular aortic repair (TEVAR) for acute type B aortic dissection complicated by mesenteric malperfusion have demonstrated that TEVAR is highly effective in expanding the true lumen and restoring normal perfusion to the downstream aorta. ${ }^{8}$ Therefore, we began to investigate hybrid treatments of ATAMM in an attempt to improve upon the dismal outcomes associated with this malperfusion syndrome. Initially we performed antegrade
TEVAR via the open arch at the time of proximal aortic replacement to stent open the true lumen of the descending thoracic aorta. Then we began to perform TEVAR first, and delay proximal aortic replacement in carefully selected patients until end-organ ischemia had resolved. ${ }^{9}$ The purpose of this study was to evaluate outcomes of the conventional and hybrid strategies used to treat ATAMM over a 14-year period at our institution.

\section{METHODS}

A retrospective review of the Emory Aortic Surgery Database identified 618 patients who underwent emergent surgical repair of an acute aortic syndrome involving the ascending aorta from 2003 to 2017. Inclusion criteria for this study were all patients who presented with an acute type A aortic dissection and diagnosed with mesenteric malperfusion. The diagnosis of mesenteric malperfusion was made using a combination of several key components of the history and physical exam, serum lab values, and radiographic findings on the initial diagnostic imaging exam. The majority of patients complained of abdominal pain in addition to chest pain. On abdominal exam, these patients had clinical findings consistent with an acute abdomen or pain out of proportion to their exam, and multiple patients had hematochezia. The presence of a lactic acidosis on the admission arterial blood gas, abnormal liver function tests, and/or prolonged prothrombin times increased the likelihood of the diagnosis. Finally, all patients had evidence on cross-sectional contrast imaging of severely compromised flow to the visceral segment of the abdominal aorta, including high-grade compression or complete obstruction of the true lumen at the level of celiac and superior mesenteric arteries. Thirty-four patients $(5.5 \%)$ met these criteria and serve as the study population. In addition to mesenteric malperfusion, these patients were frequently diagnosed with concomitant renal, ileofemoral, and/or spinal malperfusion at their initial presentation. The diagnosis of renal malperfusion was based on radiographic findings, elevated serum creatinine, and oliguria/anuria. Ileofemoral malperfusion was based upon a diminished or absent femoral pulse on physical exam, and spinal malperfusion was based on decreased or absent motor and/or sensory function in the lower extremities on physical exam. Medical records were reviewed for pre-, intra-, and postoperative variables. The Institutional Review Board at Emory University in compliance with Health Insurance Portability and Accountability Act of 1996 regulations and the Declaration of Helsinki approved this study. The Institutional Review Board waived the need for individual patient consent

The treatment algorithm for patients diagnosed with ATAMM evolved during the study period. From 2004 to 2009, patients were treated with emergent ascending aortic replacement followed by exploratory laparotomy, bowel resection, and femoral-femoral bypass as needed. Beginning in 2009, carefully selected patients received axillary-bifemoral bypass before sternotomy with perfusion of both the axillary-bifemoral graft and right axillary artery at the initiation of cardiopulmonary bypass. In 2012, endovascular techniques were incorporated into the treatment algorithm. Patients either received antegrade TEVAR deployment via the open arch under hypothermic circulatory arrest (HCA) at the time of emergent ascending/arch replacement, or a TEVAR-1st approach, consisting of emergent TEVAR followed by delayed central aortic repair. Contraindications to the TEVAR-1st approach included hemodynamic instability, cardiac tamponade, respiratory compromise, hemopericardium, intractable chest pain, evolving stroke, coronary malperfusion, or severe aortic valve insufficiency. Patients were grouped by their treatment strategy and outcomes were analyzed.

\section{Aortic Replacement}

All patients underwent resection of the primary tear, and replacement of the dissected proximal aorta with hemi- or total arch reconstruction using HCA. Concomitant antegrade or retrograde cerebral perfusion was used in 
TABLE 1. Chronologic summary of each patient's treatment algorithm, initial lab values, additional procedures, and outcomes

\begin{tabular}{|c|c|c|c|c|c|c|c|}
\hline Patient & Treatment group & Malperfused organs & $\begin{array}{l}\text { Serum lactate } \\
\quad(\mathbf{m m o l} / \mathrm{L})\end{array}$ & pH & Base deficit & Additional procedures & Outcome \\
\hline 1 & ASC/LAP & Mesenteric, renal & N/A & 7.36 & -1.3 & $\begin{array}{l}\text { Small bowel resection, } \\
\text { hemicolectomy }\end{array}$ & Dead \\
\hline 2 & ASC/LAP & $\begin{array}{l}\text { Mesenteric, renal, spinal } \\
\text { cord, ileofemoral }\end{array}$ & 5.6 & 7.32 & -2.7 & Fem-Fem bypass & Alive \\
\hline 3 & ASC/LAP & Mesenteric & 7.3 & 7.29 & -6.6 & None (diffuse intestinal ischemia ) & Dead \\
\hline 4 & ASC/LAP & Mesenteric & 5.3 & 7.13 & -14.7 & $\begin{array}{l}\text { Small bowel resection, } \\
\text { hemicolectomy }\end{array}$ & Dead \\
\hline 5 & ASC/LAP & Mesenteric & 3.2 & 7.18 & -13 & None & Alive \\
\hline 6 & ASC/LAP & Mesenteric & 2.0 & 7.39 & -1.4 & None & Alive \\
\hline 7 & Ax-Bifem/ASC & $\begin{array}{l}\text { Mesenteric, renal, } \\
\text { ileofemoral }\end{array}$ & 3.5 & 7.21 & -10.2 & Ax-Bifem bypass (pre-CPB) & Alive \\
\hline 8 & ASC/TEVAR & Mesenteric & 4.0 & 7.28 & -4 & TEVAR & Dead \\
\hline 9 & Ax-Bifem/ASC & Mesenteric, ileofemoral & 6.0 & 7.19 & -10 & Ax-Bifem bypass (pre-CPB) & Alive \\
\hline 10 & ASC/LAP & Mesenteric & 4.0 & 7.32 & -2.2 & None & Dead \\
\hline 11 & ASC/LAP & Mesenteric renal & 3.5 & 7.36 & -4.8 & Hemicolectomy & Alive \\
\hline 12 & ASC/LAP & Mesenteric & 5.0 & 7.33 & -6.7 & None (diffuse intestinal ischemia) & Dead \\
\hline 13 & ASC/TEVAR & Mesenteric, ileofemoral & 2.1 & 7.41 & -3.8 & $\begin{array}{l}\text { TEVAR, hemicolectomy, } \\
\text { Fem-Fem bypass }\end{array}$ & Dead \\
\hline 14 & ASC/LAP & Mesenteric, renal & 7.0 & 7.22 & -8.8 & $\begin{array}{l}\text { Subtotal colectomy, } \\
\text { Ax-Bifem (after aortic repair) }\end{array}$ & Dead \\
\hline 15 & ASC/LAP & Mesenteric, renal & 9.0 & 7.1 & -19 & Subtotal colectomy & Dead \\
\hline 16 & TEVAR-1st & Mesenteric, ileofemoral & 2.9 & 7.3 & -2.2 & $\begin{array}{l}\text { TEVAR } \\
\text { R iliac stent }\end{array}$ & Alive \\
\hline 17 & TEVAR-1st & $\begin{array}{l}\text { Mesenteric, renal, } \\
\text { spinal, } \\
\text { ileofemoral }\end{array}$ & 8.9 & 7.19 & -12.2 & $\begin{array}{l}\text { TEVAR } \\
\text { None }\end{array}$ & Dead \\
\hline 18 & TEVAR-1st & Mesenteric, ileofemoral & 1.2 & 7.40 & -2.1 & $\begin{array}{l}\text { TEVAR } \\
\text { R iliac stent }\end{array}$ & Alive \\
\hline 19 & TEVAR-1st & $\begin{array}{l}\text { Mesenteric, renal, } \\
\text { ileofemoral }\end{array}$ & 2.3 & 7.31 & -2.2 & $\begin{array}{l}\text { TEVAR } \\
\mathrm{R} \text { renal stent }\end{array}$ & Alive \\
\hline 20 & Ax-Bifem/ASC & Mesenteric, ileofemoral & 4.0 & 7.26 & -9 & $\begin{array}{l}\text { Ax-Bifem bypass (pre-CPB) } \\
\text { TEVAR }\end{array}$ & Alive \\
\hline 21 & TEVAR-1st & Mesenteric & 2.8 & 7.4 & -1 & $\begin{array}{l}\text { TEVAR } \\
\text { SMA stent }\end{array}$ & Dead \\
\hline 22 & TEVAR-1st & Mesenteric, renal & 5.5 & 7.34 & -7.6 & TEVAR & Alive \\
\hline 23 & ASC/TEVAR & Mesenteric, renal & 3.7 & 7.29 & -7.4 & TEVAR & Alive \\
\hline 24 & ASC/TEVAR & Mesenteric & 5.1 & 7.34 & -4.2 & TEVAR & Dead \\
\hline 25 & TEVAR-1st & Mesenteric & 2.3 & 7.37 & -3 & TEVAR & Alive \\
\hline 26 & ASC/LAP & $\begin{array}{l}\text { Mesenteric } \\
\text { Renal } \\
\text { Ileofemoral }\end{array}$ & 1.6 & 7.33 & -2.9 & $\begin{array}{l}\text { L colectomy } \\
\text { Fem-Fem bypass }\end{array}$ & Dead \\
\hline 27 & TEVAR-1st & Mesenteric & 5.0 & 7.33 & -8.9 & $\begin{array}{l}\text { TEVAR } \\
\text { Ex-Lap (diffuse intestinal ischemia) }\end{array}$ & Dead* \\
\hline 28 & ASC/TEVAR & $\begin{array}{l}\text { Mesenteric, renal, } \\
\text { ileofemoral }\end{array}$ & 3.5 & 7.26 & -6.7 & TEVAR & Dead \\
\hline 29 & TEVAR-1st & $\begin{array}{l}\text { Mesenteric, renal, } \\
\text { ileofemoral }\end{array}$ & 8.5 & 7.08 & -22 & TEVAR & Dead* \\
\hline
\end{tabular}


TABLE 1. Continued

\begin{tabular}{|c|c|c|c|c|c|c|c|}
\hline Patient & Treatment group & Malperfused organs & $\begin{array}{l}\text { Serum lactate } \\
(\mathrm{mmol} / \mathrm{L})\end{array}$ & $\mathbf{p H}$ & Base deficit & Additional procedures & Outcome \\
\hline 30 & TEVAR-1st & $\begin{array}{l}\text { Mesenteric, renal, } \\
\text { ileofemoral }\end{array}$ & 13 & 7.36 & -6 & TEVAR & Dead* \\
\hline 31 & ASC/LAP & Mesenteric & 2.9 & 7.38 & -0.4 & L colectomy & Dead \\
\hline 32 & TEVAR-1 $1^{\text {st }}$ & Mesenteric & 2.3 & 7.35 & -2.3 & TEVAR & Alive \\
\hline 33 & TEVAR-1st & $\begin{array}{l}\text { Mesenteric } \\
\text { Renal }\end{array}$ & 4.0 & 7.33 & -6.7 & TEVAR & Alive \\
\hline 34 & TEVAR-1st & Mesenteric & 7.3 & 7.55 & -0.2 & TEVAR & Dead \\
\hline
\end{tabular}

ASC/LAP, Ascending/arch replacement followed by laparotomy; N/A, not applicable; Fem-Fem, femoral-femoral artery bypass; $p r e-C P B$, precardiopulmonary bypass; $A x$-Bifem $A S C$, precardiopulmonary bypass axillary-bifemoral bypass followed by ascending/arch replacement; TEVAR, thoracic endovascular aortic repair; $A S C / T E V A R$, ascending/arch and concomitant antegrade TEVAR; TEVAR-1st, TEVAR followed by delayed ascending/arch replacement; $R$, right; $S M A$, superior mesenteric artery; $L$, left; $E x$ - LAP, exploratory laparotomy. *Died before central aortic replacement.

$94 \%$ of patients. The indication for aortic root replacement was the presence of concomitant aneurysmal disease of the sinus segments to a diameter $\geq 4.5 \mathrm{~cm}$ or extensive sinus segment destruction. The indications for total arch replacement included a primary or large secondary intimal tear in the arch, aneurysmal disease with a diameter $\geq 4.5 \mathrm{~cm}$, or extensive tissue destruction that could not be safely reconstructed with a hemiarch replacement.

\section{Endovascular Aortic Repair}

Patients receiving an antegrade TEVAR during proximal aortic repair underwent procedures in a standard operating room without fluoroscopy. After initiation of HCA and arch resection but before construction of the arch anastomosis, a thoracic endoprosthesis was deployed in the descending aorta just distal to the left subclavian artery. The arch anastomosis was performed, incorporating the endograft into the distal arch suture line.

When a patient was selected for the TEVAR-1st treatment algorithm, the initial endovascular procedure was performed in a hybrid operating room with fluoroscopy. Bilateral femoral arterial access was obtained and intravascular ultrasound (IVUS) was used to confirm true lumen wire access. Based on preoperative imaging and IVUS measurements of the adventitia-to-adventitia diameter of the dissected aorta at the distal edge of the left subclavian artery, thoracic endografts were selected with $<10 \%$ oversizing. Thoracic endografts were deployed in zone 3 within $2 \mathrm{~cm}$ of the left subclavian artery. No attempt was made to cover the primary intimal tear because the goal of the TEVAR procedure was solely to expand the true lumen and increase inflow to the visceral segment. Following deployment of the initial endograft, a repeat IUVS was performed to confirm true lumen expansion and adequate branch vessel perfusion. Additional devices were added and aortic branch vessel stenting was performed until normal perfusion of the visceral aortic segment was confirmed by abdominal aortography and femoral pressures matched right radial artery pressures. Patients were returned to the intensive care unit for aggressive intravenous fluid resuscitation before open aortic replacement.

\section{Statistical Analysis}

Categorical variables were summarized using frequencies and percentages. Continuous variable results are presented as mean \pm standard deviation. Comparisons between groups were performed using $\chi^{2}$ analysis for qualitative variables and analysis of variance for continuous variables. When the frequency of any nominal variable was $\leq 5$, a Fisher exact test was used.

\section{RESULTS}

Thirty-four patients were diagnosed with ATAMM. The mean age of all patients was $53 \pm 13$ years and $76 \%$ were men. A single patient had a confirmed connective tissue disorder and 3 patients had a history of prior cardiac surgery. In addition to mesenteric malperfusion, $17(52 \%)$ patients had renal malperfusion, 14 patients $(41 \%)$ had ilieofemoral malperfusion, 2 patients $(5.9 \%)$ presented with paraplegia from spinal cord ischemia, and 3 patients $(8.8 \%)$ presented with hematochezia. The initial mean serum lactate level upon hospital admission was $4.3 \pm 2.1 \mathrm{mmol} / \mathrm{L}$.

Four different treatment strategies were used during the series: ascending/arch replacement followed by laparotomy (ASC/LAP) $(\mathrm{n}=13)$; precardiopulmonary bypass axillary-bifemoral artery bypass followed by ascending/ arch replacement (Ax-Bifem/ASC) $(n=3)$, ASC and concomitant antegrade TEVAR (ASC/TEVAR) $(\mathrm{n}=5)$, and TEVAR-1st $(\mathrm{n}=13)$. Table 1 lists the treatment group, malperfused vascular beds, initial serum lactate level, $\mathrm{pH}$, base deficit, additional procedures in addition to aortic replacement and outcome for each patient in chronological order. Table 2 lists the pertinent preoperative characteristics of the 4 groups. There were no significant differences in age, gender, preoperative serum lactate levels, or additional malperfused vascular beds between the groups. Table 3 lists the pertinent operative data and outcomes for all groups. The ASC/LAP group had significantly lower cardiopulmonary bypass times than the ASC/TEVAR or TEVAR-1st groups. However, myocardial ischemia, and circulatory arrest times and temperatures were equivalent between groups. The majority of patients underwent root repair and hemiarch replacement. Three patients $(8.8 \%)$ underwent total arch replacement for primary arch tears, and 4 patients $(11.8 \%)$ underwent root replacement for aneurysmal disease. In the hybrid treatment groups, the extent of TEVAR coverage was significantly longer in the TEVAR-1st group (TEVAR-1st $211 \pm 55 \mathrm{~mm}$ vs ASC/ TEVAR $150 \pm 32 \mathrm{~mm} ; P=.03)$.

In the ASC/LAP group, 7 patients required subtotal colectomy, and 2 additional patients had diffuse gastrointestinal 
TABLE 2. Preoperative demographic characteristics of treatment groups

\begin{tabular}{|c|c|c|c|c|c|}
\hline Characteristic & $\begin{array}{c}\text { ASC/LAP } \\
\text { 2003-2017 }(n=13)\end{array}$ & $\begin{array}{c}\text { Ax-Bifem/ASC } \\
2009-2013(n=3)\end{array}$ & $\begin{array}{c}\text { ASC/TEVAR } \\
2009-2016(n=5)\end{array}$ & $\begin{array}{c}\text { TEVAR-1st } \\
\text { 2012-2017 }(n=13)\end{array}$ & $P$ value \\
\hline Age (y) & $57 \pm 14$ & $51 \pm 5$ & $57 \pm 15$ & $50 \pm 12$ & .520 \\
\hline Male & $10(77)$ & $2(100)$ & $5(83)$ & $9(69)$ & .865 \\
\hline Serum lactate $(\mathrm{mmol} / \mathrm{L})$ & $4.6 \pm 2.3$ & $4.8 \pm 1.8$ & $3.7 \pm 1.0$ & $4.3 \pm 2.4$ & .868 \\
\hline Prior cardiac surgery & $1(7.6)$ & $1(50)$ & 0 & $1(7.6)$ & .335 \\
\hline Renal malperfusion & $6(46.2)$ & $1(50)$ & $2(33)$ & $8(62)$ & .681 \\
\hline Ileofemoral malperfusion & $2(15.3)$ & $2(100)$ & $3(50)$ & $7(54)$ & .05 \\
\hline Spinal cord malperfusion & $1(7.6)$ & 0 & 0 & $1(7.6)$ & .999 \\
\hline Hematochezia & $1(7.6)$ & 0 & $1(17)$ & $2(15.3)$ & .738 \\
\hline Cardiac tamponade & $2(15.3)$ & $2(66.6)$ & $1(20)$ & 0 & $.024^{*}$ \\
\hline Shock & 0 & $1(33.3)$ & 0 & $3(23.1)$ & .155 \\
\hline Severe aortic insufficiency & 0 & $1(33.3)$ & $1(20)$ & 0 & .050 \\
\hline
\end{tabular}

Values are presented as mean \pm standard deviation or $\mathrm{n}(\%)$. ASC/LAP, Ascending/arch replacement followed by laparotomy; Ax-Bifem/ASC, precardiopulmonary bypass axillary-bifemoral bypass followed by ascending/arch replacement; ASC/TEVAR, ascending/arch and concomitant antegrade thoracic endovascular aortic repair; TEVAR-1st, thoracic endovascular aortic repair followed by delayed ascending/arch replacement. $* P<.05$.

necrosis that was unresectable at laparotomy. An additional patient died of intractable acidosis during the postoperative period that was believed to be due to postoperative bowel or liver ischemia. Eight patients $(62 \%)$ also had postoperative renal failure requiring dialysis. The overall mortality in the ASC/LAP group was $69.2 \%$. The 3 patients who received the Ax-Bifem/ASC strategy presented with abdominal pain; total body mottling below the umbilicus; and evidence of gastrointestinal, renal, and bilateral ileofemoral malperfusion. Two of 3 patients required postoperative dialysis, but none required laparotomy, and all were successfully discharged alive from the hospital.
In the ASC/TEVAR group, 2 patients underwent laparotomy on postoperative day 1 , required bowel resection, and ultimately expired of persistent acidosis and gastrointestinal sepsis. Two other patients, deemed too unstable for laparotomy, died as a result of postoperative severe acidosis that was considered to be secondary to gastrointestinal ischemia. All 4 of these patients required dialysis during the postoperative period. The overall mortality in the ASC/TEVAR group was $80 \%$.

In the TEVAR-1st group, the mean length of aortic endograft coverage was $211 \pm 55 \mathrm{~mm}$. Two patients required additional bare metal stenting of the visceral segment true

TABLE 3. Operative data and outcomes

\begin{tabular}{|c|c|c|c|c|c|}
\hline Variable & $\begin{array}{c}\text { ASC/LAP } \\
(n=13)\end{array}$ & $\begin{array}{c}\text { Ax-Bifem/ASC } \\
(n=3)\end{array}$ & $\begin{array}{c}\text { ASC/TEVAR } \\
(n=5)\end{array}$ & $\begin{array}{l}\text { TEVAR-1st } \\
(\mathbf{n}=\mathbf{1 0})\end{array}$ & $P$ value \\
\hline Cardiopulmonary bypass time (min) & $151 \pm 32$ & $208 \pm 37$ & $214 \pm 71$ & $263 \pm 98$ & $.046^{*}$ \\
\hline Crossclamp time (min) & $90 \pm 20$ & $131 \pm 82$ & $144 \pm 55$ & $178 \pm 78$ & .056 \\
\hline hypothermic circulatory arrest time (min) & $33 \pm 10$ & $36 \pm 7$ & $37 \pm 18$ & $43 \pm 15$ & .530 \\
\hline Bladder temp at hypothermic circulatory arrest $\left({ }^{\circ} \mathrm{C}\right)$ & $25 \pm 4.4$ & $25 \pm 3.5$ & $26 \pm 4.2$ & $27 \pm 1.6$ & .510 \\
\hline Deep hypothermic circulatory arrest $(\%)$ & $7(53.8)$ & $1(33.3)$ & $2(40)$ & $1(10)$ & .154 \\
\hline Moderate hypothermic circulatory arrest (\%) & $6(46.2)$ & $2(66.6)$ & $3(60)$ & $9(90)$ & .154 \\
\hline Antegrade cerebral perfusion $(\%)$ & $8(61.5)$ & $3(100)$ & $4(80)$ & $10(100)$ & .096 \\
\hline Retrograde cerebral perfusion $(\%)$ & $3(23.1)$ & 0 & $1(20)$ & 0 & .339 \\
\hline Hemiarch & $13(100)$ & $3(100)$ & $4(80)$ & $8(80)$ & .355 \\
\hline Root replacement & 0 & $1(50)$ & $1(17)$ & $2(20)$ & .083 \\
\hline Length of thoracic endovascular aortic repair & $\mathrm{n} / \mathrm{a}$ & $\mathrm{n} / \mathrm{a}$ & $150 \pm 32$ & $211 \pm 55$ & .028 \\
\hline Renal failure & $8(62)$ & $2(100)$ & $4(66)$ & $2(20)$ & .059 \\
\hline Postoperative bowel necrosis or acidosis & $10(77)$ & 0 & $4(66)$ & 0 & $<.001^{*}$ \\
\hline Mortality & $9(69)$ & 0 & $4(66)$ & $3(30)$ & .108 \\
\hline
\end{tabular}

Values are presented as mean \pm standard deviation or n (\%). ASC/LAP, Ascending/arch replacement followed by laparotomy; Ax-Bifem/ASC, precardiopulmonary bypass axillary-bifemoral bypass followed by ascending/arch replacement; ASC/TEVAR, ascending/arch and concomitant antegrade thoracic endovascular aortic repair; TEVAR-1st, thoracic endovascular aortic repair followed by delayed ascending/arch replacement; $n / a$, not available. ${ }^{*} P<05$ 
lumen to restore adequate visceral perfusion. Additional branch vessel stenting to resolve superior mesenteric artery $(\mathrm{n}=1)$, renal $(\mathrm{n}=1)$, or iliac $(\mathrm{n}=2)$ static malperfusion was required in 4 patients. All patients had angiographic confirmation of normal celiac, superior mesenteric artery, and renal perfusion upon completion of the TEVAR procedure. Three patients died before central aortic replacement. One patient presented with a $\mathrm{pH}$ of 7.08 and died during the TEVAR procedure due to severe acidosis despite angiographic confirmation of normal perfusion to the visceral segment. A second patient, who had a 21-hour delay between the onset of symptoms and treatment, had a persistent serum lactate level $>5 \mathrm{mmol} / \mathrm{L}$ with severe abdominal tenderness on post-TEVAR day 2 . A bedside laparotomy revealed diffuse necrosis of the small and large bowel, and the family withdrew care (Figure 1). The third patient had undergone CABG 30 days before presenting with ATAMM. The first-stage TEVAR successfully resolved the mesenteric malperfusion, but the patient remained on dialysis. While attempting to optimize the patient for redo ascending/arch replacement, the patient ruptured his aorta and died on post-TEVAR day 6 .

The remaining 10 patients normalized their serum lactate levels and underwent central aortic replacement 24 hours after the TEVAR procedure. There were 3 deaths in this subgroup, none of which were due to persistent mesenteric ischemia. One patient, with a prior history of aortic and mitral valve replacement, developed a protamine reaction after separation from cardiopulmonary bypass. This resulted in catastrophic thrombosis with clot formation in all chambers of the heart and the patient died. The second patient experienced a large middle cerebral artery territory stroke following aortic surgery and the family elected to withdraw care. The final mortality occurred on postoperative day 20 with a sudden cardiac arrest during hemodialysis. This patient's autopsy did not identify a cause of death or reveal any evidence of intestinal ischemia. The mortality in patients who underwent emergent TEVAR followed by delayed central aortic replacement was $30 \%$.

\section{DISCUSSION}

Among the many challenging aspects in the treatment of acute type A aortic dissection is the variation, unpredictability, and uniqueness of the disease presentation in each individual patient. Surgeons with experience in treating dissections understand that not all dissections are created equal and this concept can be further applied on a more granular level to the malperfusion syndromes associated with acute type A dissection. Mortality rates associated with coronary or cerebral malperfusion are high, but do not approach the $41 \%$ to $100 \%$ mortality rate reported in patients with mesenteric malperfusion. ${ }^{1-5}$ After several years of observing high mortality at our institution in treating ATAMM patients with emergent ascending aortic

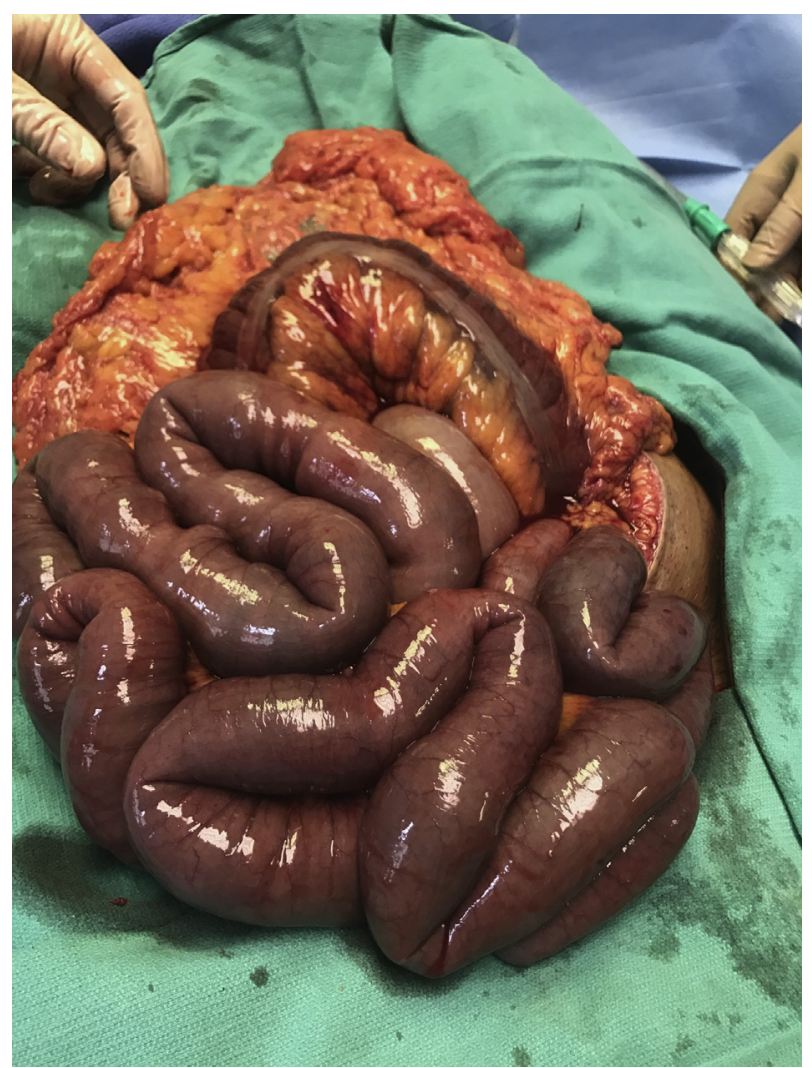

FIGURE 1. Unresectable diffuse small and large intestinal ischemia in a patient undergoing ascending and arch replacement followed by exploratory laparotomy in a patient with acute type A dissection with mesenteric malperfusion.

replacement and resection of necrotic bowel, alternative options were considered in an attempt to improve upon these dismal results. We have ultimately embraced an unconventional strategy of endovascular restoration of blood flow to the malperfused beds of the visceral aortic segment followed by delayed proximal aortic replacement. This novel approach has demonstrated improved outcomes in this initial experience, and also serves as a bridge to decision tool that provides reperfusion to the mesenteric circulation and allows for the identification of patients with unsalvageable disease before major thoracic aortic surgery.

There are multiple factors that account for the high mortality associated with ATAMM. First, making the correct diagnosis of ATAMM is challenging and is based on a constellation of clinical exam findings, laboratory studies, and radiographic features combined with a high index of suspicion. Abdominal pain is not always present, and the serum lactate may only rise late in the process when there is transmural intestinal infarction. Our index of suspicion is elevated when there is significant compression of the true lumen throughout the visceral aortic segment 
(Figure 2) on the diagnostic imaging study. Another factor is the frequent presence of concomitant renal and ileofemoral malperfusion. In the current series, $52 \%$ of patients had renal malperfusion and $41 \%$ had ileofemoral malperfusion. Effectively this signifies malperfusion to all organs below the diaphragm.

However, the main contributor to the high mortality rate in ATAMM is most likely the autoregulatory response of the splanchnic circulation to ischemia. When a significant reduction $(>75 \%)$ in blood flow to the celiac and superior mesenteric artery vascular beds occurs, the intestinal mucosal and submucosal layers become ischemic. ${ }^{10}$ This results in a compensatory vasodilatory response at the arteriolar level of the affected vascular territories. As the ischemic period becomes prolonged, the arteriolar vasodilatation converts to vasoconstriction which is often irreversible, even with the restoration of normal blood flow. ${ }^{9,10}$ There can also be a significant reperfusion injury with restoration of blood flow that further exacerbates the bowel injury. ${ }^{10}$ The intractable vasospasm of the splanchnic microcirculation combined with the additional insult of reperfusion injury is likely responsible for the high incidence of necrotic bowel/intractable acidosis that was observed in the ASC/LAP and ASC/TEVAR groups of the current study.
In several of these patients, the operative report at the time of laparotomy described the presence of a strong Doppler pulse at the root of the mesentery but an absence of distal signals in conjunction with necrotic bowel. Such findings are consistent with persistent vasospasm, the pathophysiologic process observed in nonocclusive mesenteric ischemia, and is likely a principal factor in the $60 \%$ to $80 \%$ mortality associated with acute mesenteric ischemia. $^{10}$

The key difference between the TEVAR-1st strategy and the more conventional algorithms is that the ischemic bowel, which is on the brink of irreversible injury in patients presenting with ATAMM, avoids the ischemic insult of circulatory arrest before reperfusion. Instead, pulsatile blood flow is restored to the visceral segment with minimal hemodynamic manipulation, and the severe acidosis along with intestinal perfusion is corrected before cardiopulmonary bypass, circulatory arrest, and central aortic replacement. In the 10 patients who underwent TEVAR-1st and delayed aortic replacement, there were zero cases of postoperative bowel ischemia or intractable acidosis, which has been shown to be an independent risk factor for mortality. ${ }^{11} \mathrm{We}$ believe that delaying circulatory arrest until after restoration of blood flow to the celiac and superior mesenteric

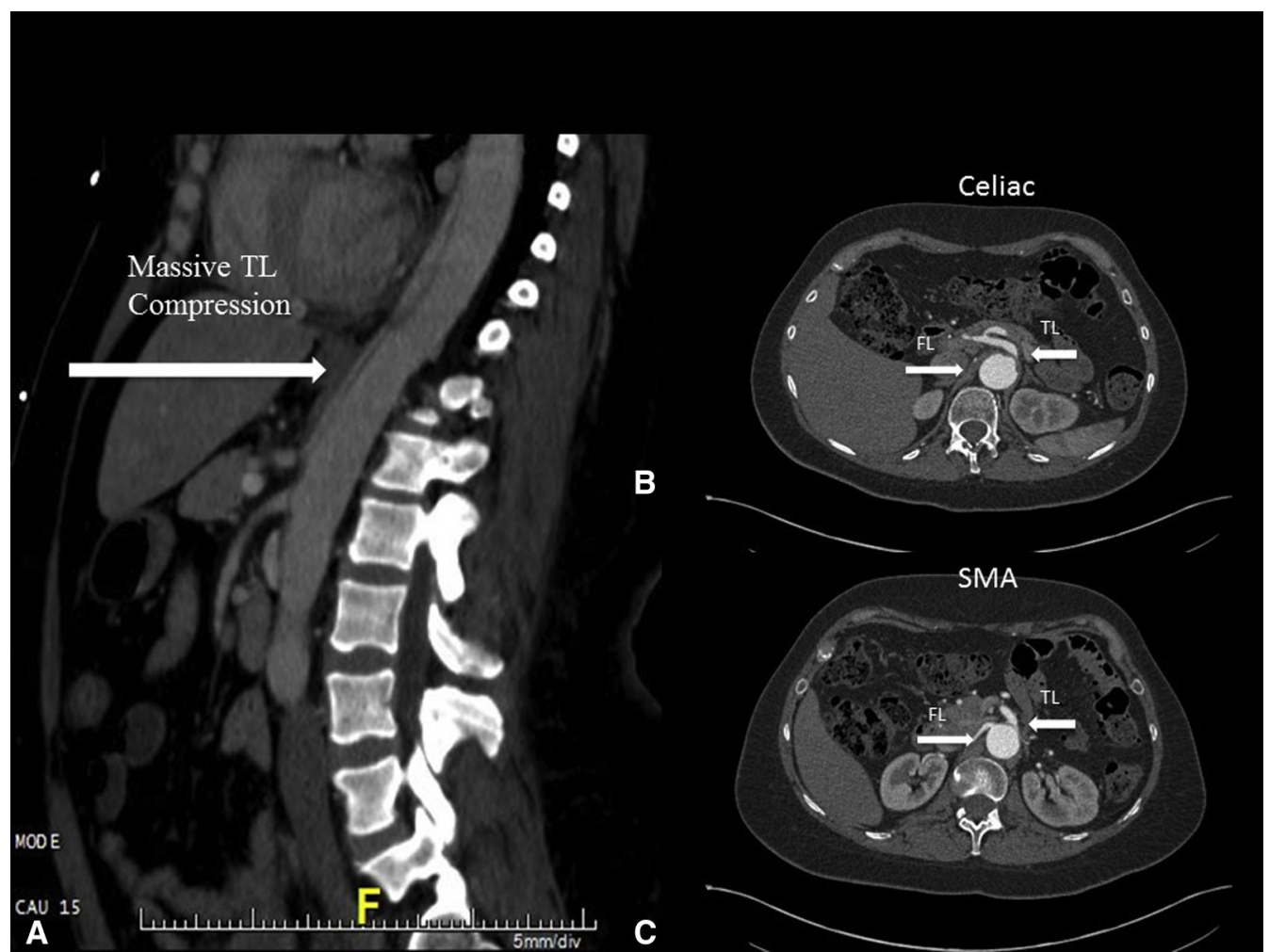

FIGURE 2. Computed tomography image features in a patient with acute type A dissection with mesenteric malperfusion. A, Coronal image of the abdominal aorta demonstrating massive true lumen $(T L)$ compression. B, Axial image of the abdominal aorta demonstrating the appearance of the celiac artery with massive TL compression. C, Axial image of the abdominal aorta demonstrating the appearance of the superior mesenteric artery (SMA) with massive TL compression. Arrows point to TL and false lumen $(F L)$. 
EMORY Algorithm for Type A with Mesenteric Malperfusion

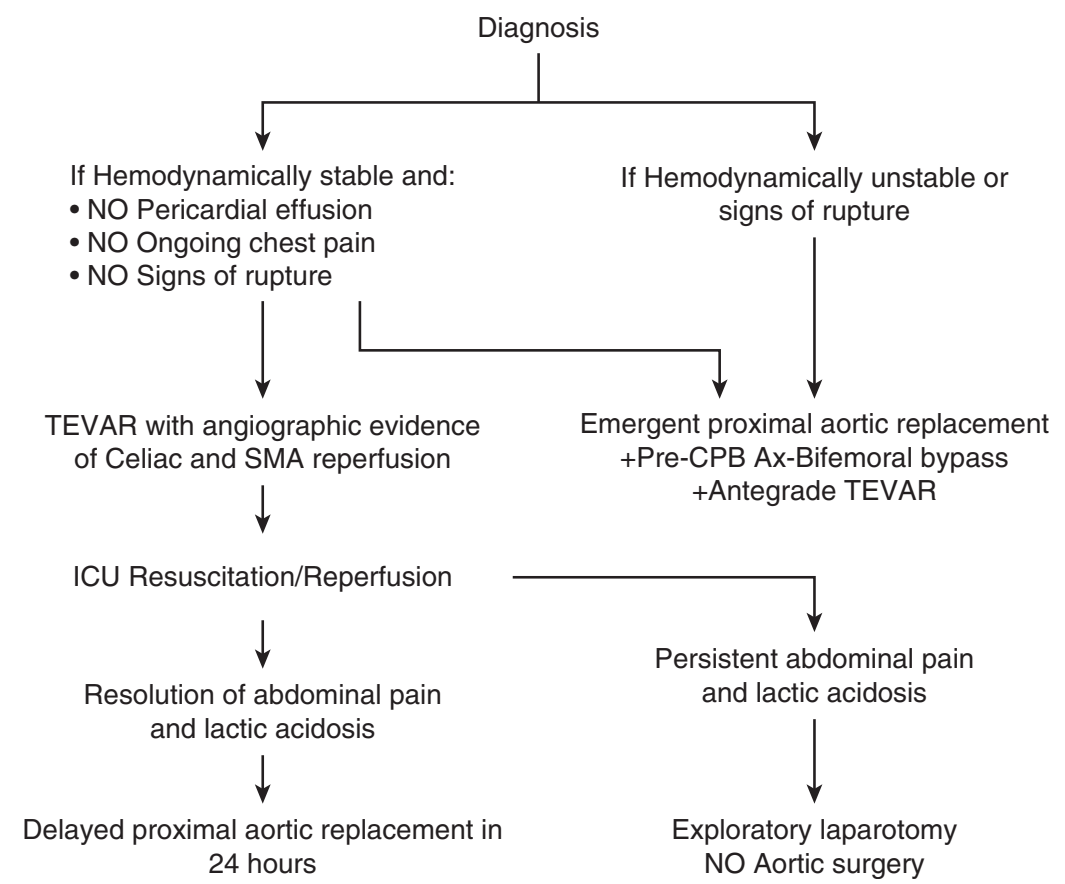

FIGURE 3. Contemporary treatment algorithm for patients presenting with acute type A aortic dissection with mesenteric malperfusion. Pre-CPB AxBifemoral bypass, Precardiopulmonary bypass axillary artery- bifemoral artery bypass; TEVAR, thoracic endovascular aortic repair; SMA, superior mesenteric artery; $I C U$, intensive care unit.

arteries prevents the lethal intractable splanchnic circulation vasospasm. This concept may also explain why all 3 patients who underwent Ax-Bifem/ASC patients did not require laparotomy and survived to discharge. Finally, it should also be noted that there was a trend toward a reduction in the need for dialysis in the TEVAR-1st group compared with the ASC/LAP and ASC/TEVAR groups. It is our opinion that reperfusion of the kidneys before HCA resulted in improved renal function in the TEVAR-1st group.

The TEVAR-1 st strategy also can also serve as a bridge to decision in patients who present with advanced mesenteric ischemia and are unlikely to survive. Three patients who underwent TEVAR-1st died before aortic replacement. One patient died on the operating room table from severe acidosis despite reperfusion of the visceral aortic segment, and the second patient had a persistent lactic acidosis, abdominal pain, and unresectable bowel necrosis at laparotomy 12 hours after TEVAR. It is unlikely that either of these patients would have survived proximal aortic replacement under HCA and were therefore spared an unnecessary invasive operation with a large use of resources. Acute type A dissection with severe acidosis and abdominal malperfusion have been demonstrated to be uniformly fatal in other large series. ${ }^{12}$ The third patient was 30 days out from a coronary artery bypass graft procedure and died of an interval aortic rupture on post-TEVAR day 6 . This case clearly illustrates the perils of prolonging delayed aortic replacement and has underscored the importance of maintaining a 24-hour rule when using the TEVAR-1st strategy.

Limitations of the current study include the small numbers, a selection bias for the TEVAR-1st group, a time bias, and the variability of end-organ ischemia in each patient. Fortunately, ATAMM is a rare (4\%-6\%) variant of type A aortic dissection; consequently, this leads to a small study population. Given the 4 different treatment strategies employed in this study, our conclusions suffer from a lack of statistical power. To be considered for the TEVAR-1st protocol, patients could not have signs of shock, cardiac tamponade, rupture, or severe aortic insufficiency. Although there were very few patients in each group that demonstrated these clinical findings (Table 2), there may have been a selection bias toward more hemodynamically stable patients in the TEVAR-1st group that could have contributed to the improved outcomes. Furthermore, the majority of patients with ATAMM in the most recent surgical era (2012-2017) were treated with the TEVAR1 st strategy and therefore benefited from improved overall surgical techniques and perioperative care, which may also have influenced the results. It is also difficult to make similar (ie, apples to apples) comparisons between groups in this study, when ATAMM can present with varying 
degrees of mesenteric, renal, and ileofemoral malperfusion and end-organ ischemia. As demonstrated in Table 1, patients can present with a relatively mild acidosis and still have diffuse unresectable intestinal ischemia (patients 3 and 12). Unfortunately there are no laboratory studies that have the sensitivity and specificity to accurately identify the presence or absence of intestinal ischemia. ${ }^{6}$ Although there were no significant differences in the lactate levels between the treatment groups, it is possible that 1 group contained patients with significantly more advanced end-organ ischemia than the others. This could influence outcomes and make one treatment strategy appear falsely inferior to the alternatives.

\section{CONCLUSIONS}

Given our experience and outcomes with various treatment strategies in patients with ATAMM, we propose an algorithm for the management of this challenging disease (Figure 3). Once the diagnosis of ATAMM is made, patients who are hemodynamically stable, free from pain, and have no evidence of severe aortic regurgitation, cardiac tamponade, or rupture (ie, hemopericardium) should be considered for TEVAR \pm additional endovascular therapy or Ax-Bifem bypass with dual antegrade and retrograde perfusion of the aorta with initiation of cardiopulmonary bypass followed by immediate central aortic replacement. If a patient undergoing TEVAR has normal lactate levels in 24 hours, he or she should be taken for central aortic replacement. If persistent lactic acidosis remains, these patients should undergo laparotomy, bowel resection, and either withdrawal of care or further delay of aortic replacement until the acidosis is resolved. Patients with ATAMM who are hemodynamically unstable, have signs of rupture, or have intractable chest or abdominal pain should undergo emergent Ax-Bifem bypass with antegrade and retrograde perfusion of the aorta, immediate ascending/arch replacement with antegrade TEVAR via the open arch, and completion of the Ax-Bifem bypass at the end of the case. We believe that the application of this contemporary algorithm to the most lethal variant of type A aortic dissection will result in improved outcomes.

\section{Webcast}

You can watch a Webcast of this AATS meeting presentation by going to: https://aats.blob.core.windows.net/ media/18AO/26-br-1630-chen-AwardGivenFirst-v2.mp4.

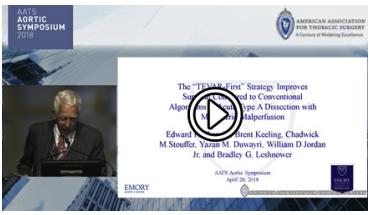

\section{Conflict of Interest Statement}

Dr Leshnower serves on the Speakers Bureau for Medtronic Inc; Dr Duwayri serves as a consultant for Cook Medical; and Dr Jordan serves as a consultant for Gore, Medtronic Inc, Cook Medical, and Cardinal Health. All other authors have nothing to disclose with regard to commercial support.

\section{References}

1. Girdauskas E, Kuntze T, Borger MA, Falk V, Mohr FW. Surgical risk of preoperative malperfusion in acute type A aortic dissection. J Thorac Cardiovasc Surg. 2009;138:1363-9.

2. Pacini D, Leone A, Belotti LM, Fortuna D, Gabbieri D, Zussa C, et al. Acute type A aortic dissection: significance of multiorgan malperfusion. Eur J Cardiothorac Surg. 2013;43:820-6.

3. Yagdi T, Atay Y, Engin C, Mahmudov R, Tetik O, Iyem H, et al. Impact of organ malperfusion on mortality and morbidity in acute type A aortic dissections. $J$ Card Surg. 2006;21:363-9.

4. DiEusanio M, Trimarchi S, Patel HJ, Hutchinson S, Suzuki T, Peterson MD, et al. Clinical presentation, management and short-term outcome of patients with acute type A aortic dissection complicated by mesenteric malperfusion: observations from the international registry of acute aortic dissection. J Thorac Cardiovasc Surg. 2013;145:385-90.

5. Patel HJ, Williams DM, Dasika NL, Suzuki Y, Deeb GM. Operative delay for peripheral malperfusion syndrome in acute type A aortic dissection: a long-term analysis. J Thorac Cardiovasc Surg. 2008;135:1288-96.

6. Bala M, Kashuk J, Moore EE, Kluger Y, Biffl W, Gomes CA, et al. Acute mesenteric ischemia: guidelines of the World Society of Emergency Surgery. World J Emerg Surg. 2017; 12:38.

7. Clair DG, Beach JM. Mesenteric ischemia. N Engl J Med. 2016;374:959-68.

8. Leshnower BG, Duwayri YM, Chen EP, Li C, Zehner CA, Binongo JN, et al. Aortic remodeling after endovascular repair of complicated acute Type B aortic dissection. Ann Thorac Surg. 2017;103:1878-85.

9. Leshnower BG, Veeraswamy RK, Duwayri YM, Chen EP. The "TEVAR-first" approach to DeBakey I aortic dissection with mesenteric malperfusion. Ann Thorac Surg. 2014;97:693-6.

10. Brandt LJ, Feuerstadt P. Intestinal ischemia. In: Feldman M, Friedman LS, Brandt LJ, eds. Sleisenger and Fordtran's Gastrointestinal and Liver Disease. 10th ed. Philadelphia: Saunders; 2016:2076-101.

11. Czerny M, Schoenhoff F, Etz C, Englberger L, Khaladj N, Zierer A, et al. The impact of pre-operative malperfusion on outcome in acute type A aortic dissection. Results from the GERAADA registry. J Am Coll Cardiol. 2015;65: 2628-35.

12. Lawton JS, Moon MR, Liu J, Koerner DJ, Kulshrestha K, Damiano RJ Jr, et al. The profound impact of combined severe acidosis and malperfusion on operative mortality in the surgical treatment of type A aortic dissection. J Thorac Cardiovasc Surg. 2018;155:897-904.

Key Words: aortic dissection, thoracic endovascular aortic repair, mesenteric ischemia 